\title{
RAPD E ITS DETECTAN VARIACIÓN MOLECULAR EN POBLACIONES CHILENAS DE Beauveria bassiana
}

\author{
RAPD and ITS reveal molecular variation of Chilean populations \\ of Beauveria bassiana
}

\author{
Viviana Becerra V. ${ }^{1}$, Mario Paredes C. ${ }^{1}$, Carmen Rojo M. ${ }^{1}$, y Andrés France $\mathbf{I}^{1}$
}

\begin{abstract}
A B S T R A C T
Entomopathogenic fungi are an attractive alternative for the biological control of insects. In Chile, the Quilamapu Regional Research Center of the National Agricultural Research Institute (INIA) has collected about 400 isolates of the genus Beauveria along the country. A partial classification of this collection has been based on morphology and efficiency as biological control agents. It is necessary to complement this characterization with genetic molecular markers, to determine the level of genetic diversity in Chilean Beauveria bassiana populations and to identify banding patterns that discriminate among isolates from a representative sample of the B. bassiana collection. The analysis was done using Random Amplified Polymorphic DNA (RAPD) and Polymerase Chain Reaction-Restriction Fragment Length Polymorphism (PCR-RFLP) of Internal Transcribed Spacer (ITS)-rDNA sequences. The RAPD analysis indicated high genetic diversity among the isolates, with a $43 \%$ of similarity on the average. RAPD were more efficient at identifying isolates. On the other hand, the ITS analysis determined a lower diversity, with an $83 \%$ of similarity among the isolates. The low number of haplotypes did not allow discrimination among isolates. ITS 1 region showed a higher number of restriction sites, compared to ITS 2 region. For the two molecular markers, genetic diversity was not associated with the geographical origin of the isolates.
\end{abstract}

Key words: entomopathogenic fungi, genetic diversity, RAPD, Internal Transcribed Spacer (ITS).

\section{R E S U M E N}

Los hongos entomopatógenos son una alternativa atractiva para el control biológico de insectos plagas. En Chile, el Instituto de Investigaciones Agropecuarias (INIA), Centro Regional de Investigación Quilamapu mantiene aproximadamente 400 aislamientos de Beauveria, colectados a través del país. Esta colección ha sido parcialmente clasificada en base a su morfología y a su eficacia como controlador biológico. Sin embargo, es necesario complementar estos estudios con una caracterización a nivel genético-molecular, para determinar el nivel de diversidad genética de Beauveria bassiana e identificar posibles patrones de bandas que permitan discriminar entre aislamientos. En este estudio, se analizaron 36 aislamientos de $B$. bassiana provenientes de diversas regiones geográficas del país. El análisis genético se realizó mediante el ADN Polimórfico Amplificado al Azar (RAPD) y la Reacción en Cadena de la Polimerasa-Fragmentos de Restricción Polimórficos (PCR-RFLP) de los espaciadores internos transcritos (ITS) de las secuencias ribosomales del ADN (ITSrDNA). El análisis de RAPD indicó una alta diversidad genética entre los aislamientos, con un promedio de $43 \%$ de similitud. Por otro lado, el análisis de los ITS determinó una menor diversidad, con un $83 \%$ de similitud entre aislamientos. La región ITS 1 mostró un mayor número de sitios de restricción que la región ITS 2. Los RAPD fueron más eficientes para discriminar (o identificar) entre cepas debido al bajo número de haplotipos detectados con los ITS. Para los dos marcadores utilizados en este estudio, la diversidad genética no estuvo asociada con el origen geográfico de los aislamientos.

Palabras clave: hongos entomopatógenos, diversidad genética, RAPD, espaciadores internos transcritos (ITS).

\footnotetext{
Financiamiento: Proyecto FONDECYT N ${ }^{\circ} 1030037$.

${ }^{1}$ Instituto de Investigaciones Agropecuarias, Centro Regional de Investigación Quilamapu, Casilla 426, Chillán, Chile. E-mail: vbecerra@inia.cl *Autor para correspondencia.

Recibido: 9 de marzo de 2006. Aceptado: 20 de abril de 2006.
} 


\section{INTRODUCCIÓN}

En la naturaleza los hongos entomopatógenos (HEP) pueden controlar o mantener las plagas en niveles que no ocasionan daños económicos a los cultivos (Azevedo y Melo, 1998). Estos hongos se encuentran en rastrojos de cultivos, estiércol, suelo, y plantas, alcanzando un buen desarrollo en lugares frescos, húmedos y con baja luminosidad. Los HEP son el grupo de mayor importancia en el control biológico de insectos-plagas. Prácticamente, todos los insectos son susceptibles a algunas de las enfermedades causadas por estos hongos (López y Börjes, 2001). Actualmente se conocen aproximadamente 100 géneros y 700 especies de HEP; entre los géneros más importantes están Metarhizium, Beauveria, Aschersonia, Entomophthora, Zoophthora, Erynia, Eryniopsis, Akanthomyces, Fusarium, Hirsutella, Hymenostilbe, Paecelomyces y Verticillium (López y Börjes, 2001), siendo los más utilizados Beauveria (Zurek y Keddie, 2000; Mulock y Chandler, 2000) y Metarhizium (Ferron et al., 1991).

Desde 1996, el Instituto de Investigaciones Agropecuarias (INIA), en el Centro Regional de Investigación (CRI) Quilamapu, Chillán, estableció un Programa de Patología de Insectos, cuyo objetivo fue prospectar, aislar e identificar organismos entomopatógenos a lo largo de Chile, para su uso como controladores biológicos de plagas (France et al., 2000). En esta colección se mantienen alrededor de 400 aislamientos de Beauveria bassiana (Balsamo) Vuillemin. Esta especie es de importancia mundial, ya que ha sido evaluada como agente controlador de varias especies de insectos-plagas de importancia económica (Maurer et al., 1997; Zurek y Keddie, 2000).

La colección de $B$. bassiana ha sido clasificada desde el punto de vista morfológico y en su eficiencia como controlador biológico (France et al., 2000; 2002) y necesita de una clasificación genética molecular para detectar diferencias a nivel de ADN y para complementar los datos morfológicos obtenidos.

En general, una de las principales desventajas de la caracterización morfológica es que las características a medir son limitadas en número, por lo cual la discriminación entre aislamientos es difícil. Por otro lado, la presencia de estas especies en diversos climas y condiciones agroecológicas, indicaría la existencia de una alta variabilidad genética en la especie.
Actualmente, la forma más certera de determinar los niveles de diversidad y estructura genética intraespecífica es a través del uso de marcadores moleculares. Principalmente se han usado cuatro tipos de marcadores moleculares para determinar la diversidad genética en HEP: los fragmentos de restricción polimórficos (RFLP) (Maurer et al., 1997), el ADN polimórfico amplificado al Azar (RAPD) (Piatti et al., 1998; Gaitan et al., 2002), las secuencias simples repetidas (SSR) (Kretzner et al., 2000); y los espaciadores internos transcritos (ITS), ITS 1 y 2 del rADN (Buscott et al., 1996; Coates et al., 2002). Todos estos marcadores han sido efectivos determinando diferencias genéticas entre aislamientos, pero en forma complementaria y con un poder de discriminación diferente entre ellos (Couteaudier et al., 1998). En Chile $B$. bassiana ha sido poco estudiada utilizando marcadores moleculares.

La metodología mayormente usada en estudios de diversidad genética han sido los RAPDs, técnica basada en PCR (Williams et al., 1990). En el caso específico de los HEP, los RAPDs han determinado la diversidad genética en dos especies del género Beauveria (Neuvéglise et al., 1994; Neuvéglise y Brygoo, 1994; Bidochka et al., 1995; Maurer et al., 1997). También estos marcadores han sido utilizados para asociar patrones específicos a índices de patogenicidad (Piatti et al., 1998; Valderrama et al., 2000; Sivaramakrishnan et al., 2002; Gaitan et al., 2002). Por otro lado, las secuencias ribosomales nucleares, especialmente los ITS 1 y 2 , han mostrado tasas diferenciales en cambios nucleotídicos, lo cual permite la comparación de aislamientos a nivel inter e intraespecífico en hongos (Neuvéglise et al., 1994; Buscott et al., 1996; Iturralde, 2005). Para amplificar las regiones ITS 1 e ITS 2 se han diseñado partidores universales que amplifican estas zonas genéticamente conservadas para establecer su nivel de diversidad (White et al., 1990). Shih et al. (1995) indican que en B. bassiana existe un mayor nivel de mutación dentro de la región ITS 1, comparada con la región ITS 2, la cual no mostró variabilidad. Sin embargo, en otro estudio se encontró una mayor variación de secuencia en el ITS 2 de $B$. brogniartii, proveniente de un único huésped (Neuvéglise y Brygoo, 1994). Por otro lado, al menos cinco RFLPs se han detectado entre especies de Beauveria (Neuvéglise et al., 1994; Glare e Inwood, 1998) para las regiones ITS, consideradas como secuencias conservadas. 
De acuerdo a lo anteriormente expuesto, en este estudio se plantean los siguientes objetivos: a) determinar el nivel de diversidad genética que existe en poblaciones de $B$. bassiana colectadas en diferentes regiones geográficas de Chile, mediante RAPD y PCR-RFLP de los ITS 1 y 2 , intrones ubicados entre los genes rADN $28 \mathrm{~S}$ y $18 \mathrm{~S}$; y b) determinar si existen patrones genéticos únicos para ser utilizados en la discriminación de aislamientos usados en control biológico.

\section{MATERIALES Y MÉTODOS}

\section{Material genético}

Del total de la colección criopreservada, se analizaron 36 accesiones de B. bassiana (Cuadro 1) mediante RAPD y PCR-RFLP de los ITS. Los aislamientos seleccionados se colectaron en diferentes regiones geográficas del país y a partir de diferentes fuentes de inóculo. El número de aislamientos analizados corresponde a un $10 \%$ de la colección exis-

Cuadro 1. Aislamientos de Beauveria bassiana analizadas mediante RAPD ${ }^{1}$ e ITS-rDNA ${ }^{2}$.

Table 1. Beauveria bassiana isolates analized by RAPD ${ }^{1}$ and ITS-rDNA ${ }^{2}$.

\begin{tabular}{|c|c|c|}
\hline $\begin{array}{l}\text { Identificación } \\
\text { aislamientos }\end{array}$ & Fuentes de inóculo & Localidad, región \\
\hline Qu-B72 & Adulto, Listronotus bonariensis & Osorno, $\mathrm{X}$ \\
\hline Qu-B179 & Pradera natural & Pumanzano, Chiloé insular, X \\
\hline Qu-B187 & Muestra suelo, pradera natural & Osorno, Quema del buey, X \\
\hline Qu-B211 & Desconocido & Desconocido \\
\hline Qu-B221 & Muestra suelo, renoval & Bahía Mansa, Osorno, X \\
\hline Qu-B249 & Muestra suelo & Cañete, VIII \\
\hline Qu-B295 & Muestra suelo, bofedal & Chungará, I \\
\hline Qu-B299 & Muestra suelo & Lago Chungará, km 212, I \\
\hline Qu-B306 & Muestra suelo & Chaca, lado riego, Arica, I \\
\hline Qu-B314 & Larva curculiónido & Santa Lucía Alto, Yungay, VIII \\
\hline Qu-B321 & Muestra suelo & Osorno, Puyehue, X \\
\hline Qu-B323 & Muestra suelo & Río Chaca, Arica, I \\
\hline Qu-B326 & Muestra suelo & Melipilla, RM \\
\hline Qu-B328 & Muestra suelo, pradera espino & Lago Rapel, VI \\
\hline Qu-B330 & Muestra suelo & Esquina El Tambo, Vicuña, IV \\
\hline Qu-B351 & Suelo & Tirúa, Cañete, VIII \\
\hline Qu-B365 & Suelo & El Morro, Chanco, VII \\
\hline Qu-B373 & Suelo & Las Cardas, IV \\
\hline Qu-B390 & Suelo & Pelluhue, VII \\
\hline Qu-B428 & Muestra suelo, pradera natural & Soc. Campesina Agroind. Puyehue, Osorno, X \\
\hline Qu-B466 a & Suelo & Termas de Chillán, VIII \\
\hline Qu-B466 b & Suelo & Termas de Chillán, VIII \\
\hline Qu-B492 & Urocerus sp. & Trosquilmo, $\mathrm{X}$ \\
\hline Qu-B620 & Suelo & Lonquimay, IX \\
\hline Qu-B768 & Bosque nativo & Puerto Ibáñez, Cerro Castillo, X \\
\hline Qu-B771 & Pradera natural & Balmaceda, XI \\
\hline Qu-B774 & Pradera natural & Puerto Cisnes, $\mathrm{X}$ \\
\hline Qu-B796 & Suelo, turba & Punta Arenas, XII \\
\hline Qu-B798 a & Suelo & Pencahue, Fundo Bagio, VII \\
\hline Qu-B798 b & Suelo & Pencahue, Fundo Bagio, VII \\
\hline Qu-B798c & Suelo & Pencahue, Fundo Bagio, VII \\
\hline Qu-B941 & Polistes gallicus & Coihueco, Fundo El Maitén, VIII \\
\hline Qu-B903 & Suelo & Anaquena, Isla de Pascua, V \\
\hline Qu-B911 & Muestra suelo & Ahu Hanga Tere, Isla de Pascua, V \\
\hline Qu-B926 & Larva, Cydia pomonella & Río Bueno, X \\
\hline Qu-B931 & Larva, Dalaca pallens & Remehue, Osorno, X \\
\hline
\end{tabular}

${ }^{1}$ RAPD: Amplificación de ADN al Azar, Random amplified polymorphic DNA.

${ }^{2}$ ITS-rDNA: Espaciadores internos transcritos-secuencias ribosomales del ADN, Internal transcribed spacer-ribosomal DNA sequences. 
tente para esta especie. El estudio se realizó en el Laboratorio de Biotecnología de INIA Quilamapu, Chillán.

A partir de aislamientos multi-espóricos, cultivados en placas Petri a $27^{\circ} \mathrm{C}$ por 3 días en medio PDA, se realizaron cultivos monospóricos. Vale decir, esporas únicas se cultivaron en medio líquido Sabouraud más $1 \%$ de extracto de levadura y se produjo el micelio para la extracción de ADN.

\section{Extracción de ADN}

El micelio se maceró con el tampón compuesto por: $100 \mathrm{mM}$ Trizma; $1,4 \mathrm{M} \mathrm{NaCl}_{2} ; 20 \mathrm{mM}$ EDTA; $1 \%$ Polivinilpirrolidona y $2 \% \mathrm{CTAB}$, ajustado a un $\mathrm{pH}$ 8,0 ; a cada muestra se le agregaron $8 \mu \mathrm{L}$ de proteinasa K. La mezcla se incubó a $65^{\circ} \mathrm{C}$ por $60 \mathrm{~min}$ y se homogeneizó a intervalos de $10 \mathrm{~min}$. Las muestras se dejaron enfriar y se mezclaron con cloroformoisoamílico (24:1), posteriormente se centrifugaron a 5.000 r.p.m. por $15 \mathrm{~min}$, para la separación de fases, etapa que se realizó dos veces. El sobrenadante acuoso se transfirió de tubo y se le agregó isopropanol, las muestras se incubaron a $-20^{\circ} \mathrm{C}$ por toda la noche para precipitar el ADN. El pellet de ADN se colectó mediante centrifugación, se lavó con alcohol $70 \%$ y alcohol absoluto $90 \%$ para luego ser secado a temperatura ambiente. Finalmente, el ADN se diluyó en TE pH 8,0 y se trató con ribonucleasa. Para verificar la calidad del ADN se realizó una electroforesis en agarosa al $1 \%$; usando $\lambda$ Hind III como estándar de referencia.

\section{Análisis de RAPD}

Las condiciones de amplificación de los RAPD fueron de 40 ciclos de $35 \mathrm{~s}$ a $94^{\circ} \mathrm{C}, 35 \mathrm{~s}$ a $40^{\circ} \mathrm{C}$ y $1 \mathrm{~min}$ a $72^{\circ} \mathrm{C}$, con un ciclo final de $10 \mathrm{~min}$ a $72^{\circ} \mathrm{C}$ (Termociclador PTC-220, MJ Research, Massachusetts, USA) . Las reacciones se realizaron en un volumen total de $25 \mu \mathrm{L}$ que contenían $0,2 \mathrm{mM}$ de cada dNTP, $0,2 \mathrm{mM}$ del partidor, $1 \mathrm{x}$ de tampón de amplificación de PCR, 0,3 mM de $\mathrm{MgCl}_{2}$, $1 \mathrm{U}$ Taq ADN polimerasa (Invitrogen) and $25 \eta \mathrm{g}$ de ADN molde en agua ultrapura. Las reacciones se realizaron dos veces para determinar la consistencia de los patrones obtenidos y para la selección de los partidores.

Los productos de la amplificación se separaron en un gel de agarosa $(1,5 \%)$ en el tampón 1x TAE (40 $\mathrm{mM}$ Tris acetate, $1 \mathrm{mM}$ EDTA, $\mathrm{pH} 8,0$ ) a $100 \mathrm{~V}$ por 3,5 h. Los geles se tiñeron con bromuro de etidio y se fotografiaron bajo la luz ultravioleta (Translumi- nador Cole Palmer, FLUO-LINK FLX, Francia) para su posterior evaluación.

Se realizó un pre-screening sobre cinco aislamientos de B. bassiana con 39 partidores de las series OPA-A, OPA-D, OPA-AB, y OPA-M (OPERON TECHNOLOGIES, California, USA).

\section{Análisis de espaciadores internos transcritos (ITS)}

Los partidores universales ITS 1, ITS 2, ITS 3, ITS 4 e ITS 5 se utilizaron para amplificar ADN de los aislamientos mediante PCR (White et al., 1990). La reacción de PCR se realizó en un volumen total de $25 \mu \mathrm{L}$, la cual contuvo $0,2 \mathrm{mM}$ de dNTPs, $0,2 \mathrm{mM}$ de los partidores ITS $\left(3^{\prime} \rightarrow 5^{\prime}\right)$ y $\left(5^{\prime} \rightarrow 3^{\prime}\right), 1 x$ de tampón de amplificación de PCR, 0,25 $\mathrm{mM}$ de $\mathrm{MgCl}_{2}, 1 \mathrm{U}$ Taq ADN polimerasa (Invitrogen) y 25 $\eta \mathrm{g}$ de ADN molde. La amplificación se realizó en el termociclador PTC-220 (MJ Research), donde el programa incluyó un ciclo inicial de 3 min a $94^{\circ} \mathrm{C}$, seguido por 35 ciclos de $30 \mathrm{~s} 94^{\circ} \mathrm{C}, 40$ s $57^{\circ} \mathrm{C}$, y 20 min a $72^{\circ} \mathrm{C}$. La restricción de los productos de PCR se realizó de acuerdo a protocolos de los distribuidores usando las siguientes enzimas endonucleasas: Acc I, Alu I, Dde I, Eco RI, Eco RV, Hae III, Hha I, Hinf I, Hpa II, Mbo I, Mse I, Msp I, Nde II, $R s a$ I, Sin I, Tru 9I y Xho I. La reacción de digestión se realizó bajo las siguientes condiciones: $10 \mu \mathrm{L}$ de ADN amplificado, 1x tampón (tampón enzimaespecífico) y 5 a 8 unidades de enzima de restricción. La incubación fue a $37^{\circ} \mathrm{C}$ en un tiempo adecuado a la enzima de restricción.

Los fragmentos generados por la restricción se separaron mediante electroforesis en un gel de poliacrilamida al 6\% (20x20) en el tampón 1x TBE a $100 \mathrm{~V}$ por $2 \mathrm{~h}$. El gel se tiñó con bromuro de etidio para visualizar los fragmentos bajo la luz UV. Los pesos moleculares de los fragmentos se determinaron usando como estándar la escalera de ADN de 100 pb y el programa 1D Image Analysis Program (Kodak).

\section{Análisis de los datos}

Para los RAPD e ITS, las bandas se consideraron como caracteres binarios y se evaluaron como "1" cuando hubo presencia y " 0 " cuando hubo ausencia de ellas. La similitud genética entre pares se estimó mediante el coeficiente de Jaccard con la opción SIMQUAL. La matriz de similitud se analizó a través del "Sequential, agglomerative, hierarchical and nested clustering" (SAHN) (Sneath y Sokal, 
1973). Los dendrogramas se generaron usando el método jerárquico y el algoritmo de agrupamiento de UPGMA. El programa MXCOMP se usó para calcular la matriz de correlación cofenética entre la matriz de similitud y la matriz original para determinar si los datos originales estaban bien representados en el análisis de agrupamiento, bajo 1.000 permutaciones. Todos los análisis se realizaron con el programa NTSYSpc 2.1 (Rohlf, 2000).

Para el análisis de RAPD e ITS, se determinó la existencia de patrones de bandas específicos para la identificación de aislamientos.

\section{RESULTADOS Y DISCUSIÓN}

\section{Análisis de RAPD en Beauveria bassiana}

Veinte partidores de RAPD fueron seleccionados, basados en su reproducibilidad, después del pre- screening para analizar los 36 aislamientos de $B$. bassiana. Un total de 173 bandas fueron determinadas, de las cuales $98,3 \%$ fueron polimórficas. El número de bandas por partidor varió entre 3 (OPM01) y 15 (OPA-13), con un promedio de 8,7 bandas por partidor. El rango de estos resultados concuerda con los datos obtenidos por Gaitan et al. (2002) en $B$. bassiana, lo cual indica la consistencia y utilidad de estos marcadores en estudios de diversidad genética.

Diez de los 20 partidores fueron los más informativos (OPA-13; OPD-18; OPAB-09; OPA-11; OPD03; OPD-13; OPAB-06; OPAB-11; OPAB-14 y OPAB-18), con ellos se detectó un $68,8 \%$ del polimorfismo total. Estos partidores generaron el mayor número de patrones de bandas (entre $10 \mathrm{y}$ 12), lo cual los sugiere como buenos partidores para hacer un "fingerprinting".

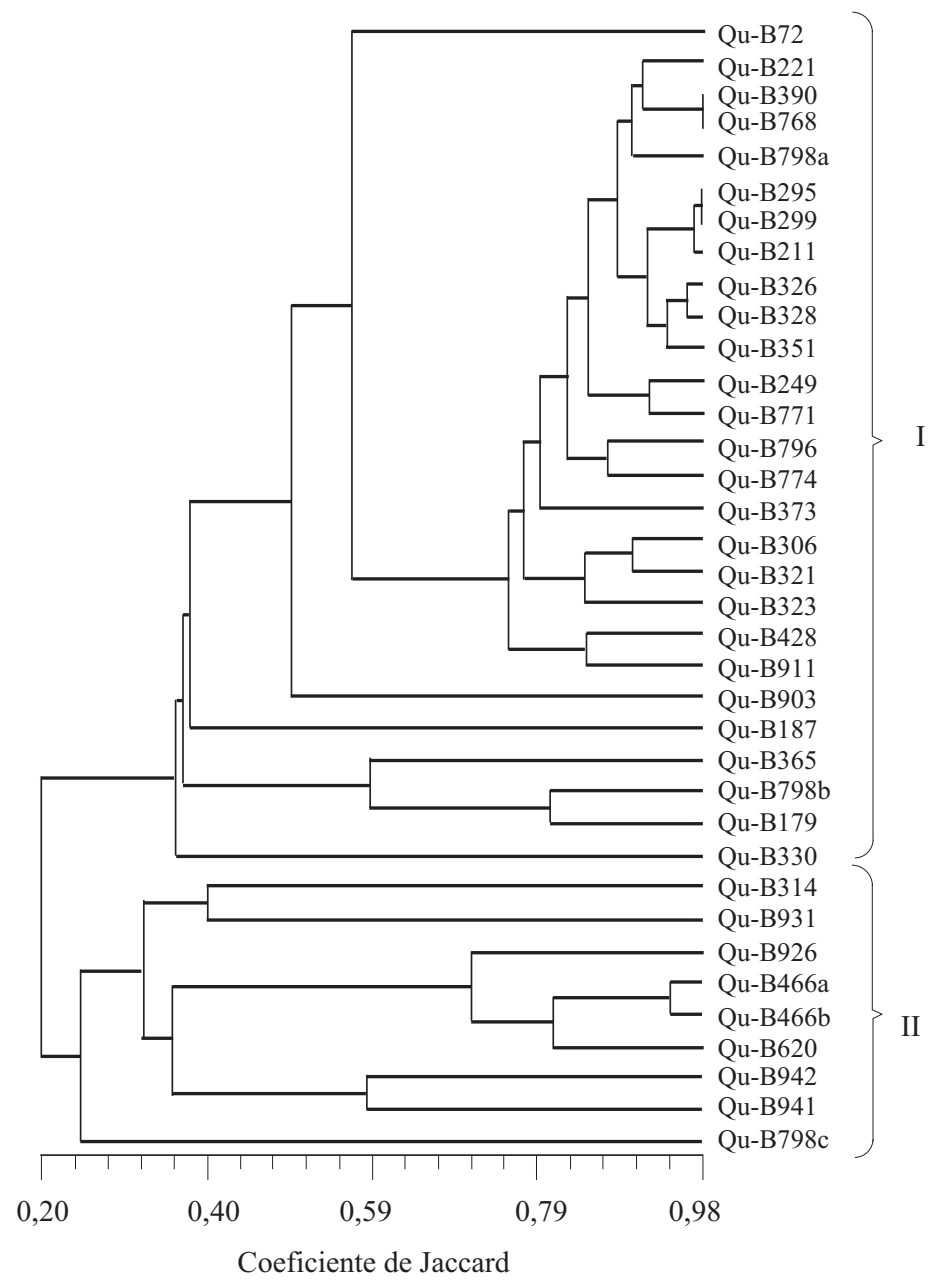

Figura 1. Dendrograma generado por análisis de RAPD en aislamientos de Beauveria bassiana chilena. Figure 1. Dendrogram from RAPD analysis of Chilean Beauveria bassiana isolates. 
El dendrograma de B. bassiana agrupó los 36 aislamientos con un promedio de similitud de $42,3 \%$ (Figura 1). En la figura se observan dos grupos principales. El primero de ellos incluyó 27 aislamientos (desde Qu-B72 a Qu-B330), este grupo incluyó aislamientos colectados en el norte (I Región), centro (V, VI, VII regiones) y sur del país (VIII y X regiones), incluyendo dos aislamientos colectados en la Isla de Pascua (Qu-B911 y QuB903). El promedio de similitud de este grupo fue de un $70 \%$, lo cual indica una variabilidad genética intermedia a baja. Veintiséis de estos aislamientos fueron colectados desde el suelo y uno de un adulto de Listronotus bonariensis.

El segundo grupo, de nueve aislamientos (desde Qu-B314 a Qu-B798c), fue colectado en el área sur del país, con la excepción de Qu-B798c que es de la VI Región (Figura 1). Glare e Inwood (1998) indican que el origen geográfico influenció el número de haplotipos observados y la estructura genética de B. bassiana cuando la comparación se realizó entre aislamientos endógenos de Nueva Zelanda y Europa y entre Nueva Zelanda y América del Sur. Por otro lado, Coates et al. (2002) sugieren que la geografía puede no jugar un rol sobre la diversidad genética, dependiendo del caso. En este grupo, cinco de los nueve aislamientos fueron colectados de diferentes insectos: larvas de Curculionideae, Cydia pomonella, Dalaca pallens, Urocerus sp. y Polister gallicus (Figura 1).

El agrupamiento de las poblaciones indicó una escasa asociación entre el origen geográfico de los aislamientos y la diversidad genética. Por ejemplo, Qu-B390 colectada en la VII Región (Pelluhue, lat. $35^{\circ} 49^{\prime}$ ) fue genéticamente similar a Qu-B768 de la X Región (Puerto Ibáñez, lat. 4545') (Figura 1). Por otro lado, dentro de este primer grupo, algunos aislamientos provenientes de la misma región fueron genéticamente distintos entre ellos. Es así como Qu-B295, Qu-B306 y Qu-B323, provenientes de la I Región (Arica) no fueron agrupados juntos, aunque Qu-B295 y Qu-B299 fueron los más cercanos genéticamente, ambos colectados en la misma localidad de Chungará (lat. 18¹5') (Figura 1). Este hecho confirma que los aislamientos chilenos de $B$. bassiana tienen una amplia diversidad genética dentro y entre regiones del país (Figura 1). Esta diversidad entre regiones ha sido también detectada en B. brongniartii (Piatti et al., 1998).

El coeficiente de correlación cofenético entre la matriz cofenética y los datos originales de los RAPD fue de 0,92 . Este valor fue alto y mostró que la matriz original está bien representada en el dendrograma.

\section{Análisis de ITS en Beauveria bassiana}

Las regiones ITS 1 e ITS 2 fueron amplificadas por los partidores universales, $1-2$ y 3-4, respectivamente (White et al., 1990). En ambas regiones se generó un fragmento único en todos los aislamientos, los cuales fueron digeridos con varias enzimas de restricción. Estas enzimas generaron varias diferencias a nivel molecular entre los 36 aislamientos de $B$. bassiana. En la región ITS 1 con la enzima de restricción $A l u$ I se detectaron fragmentos desde 230 a 220 pb, con Hae III desde 130 a 90 pb, con

Cuadro 2. Fragmentos de restricción (RFLP) observados después de la electroforesis PAGE de los aislamientos de Beauveria bassiana analizados mediante ITS-rDNA ${ }^{1}$.

Table 2. Restriction fragments (RFLP) observed after PAGE electrophoresis of Beauveria bassiana isolates analized by ITS-rDNA ${ }^{1}$.

\begin{tabular}{|c|c|c|c|}
\hline & \multicolumn{3}{|c|}{$\begin{array}{c}\text { Fragmentos de restricción (RFLP) } \\
(\mathrm{pb})\end{array}$} \\
\hline & Haplotipo 1 & Haplotipo 2 & Haplotipo 3 \\
\hline \multicolumn{4}{|l|}{ ITS 1} \\
\hline$A l u \mathrm{I}$ & 230 & 220 & \\
\hline Hae III & 130 & 130,90 & \\
\hline Hha I & 240 & 220 & \\
\hline Nde II & 190 & 180 & \\
\hline Hinf I & $110,80,30$ & $190,80,30$ & $180,80,30$ \\
\hline \multicolumn{4}{|l|}{ ITS 2} \\
\hline Alu $\mathrm{I}$ & 240,110 & 350 & \\
\hline Hae III & 190,70 & 185,70 & \\
\hline$H h a \mathrm{I}$ & 290,80 & $160,140,80$ & \\
\hline
\end{tabular}

${ }^{1}$ ITS-rDNA: Espaciadores internos transcritos-secuencias ribosomales del ADN, Internal transcribed spacer-ribosomal DNA sequences. 

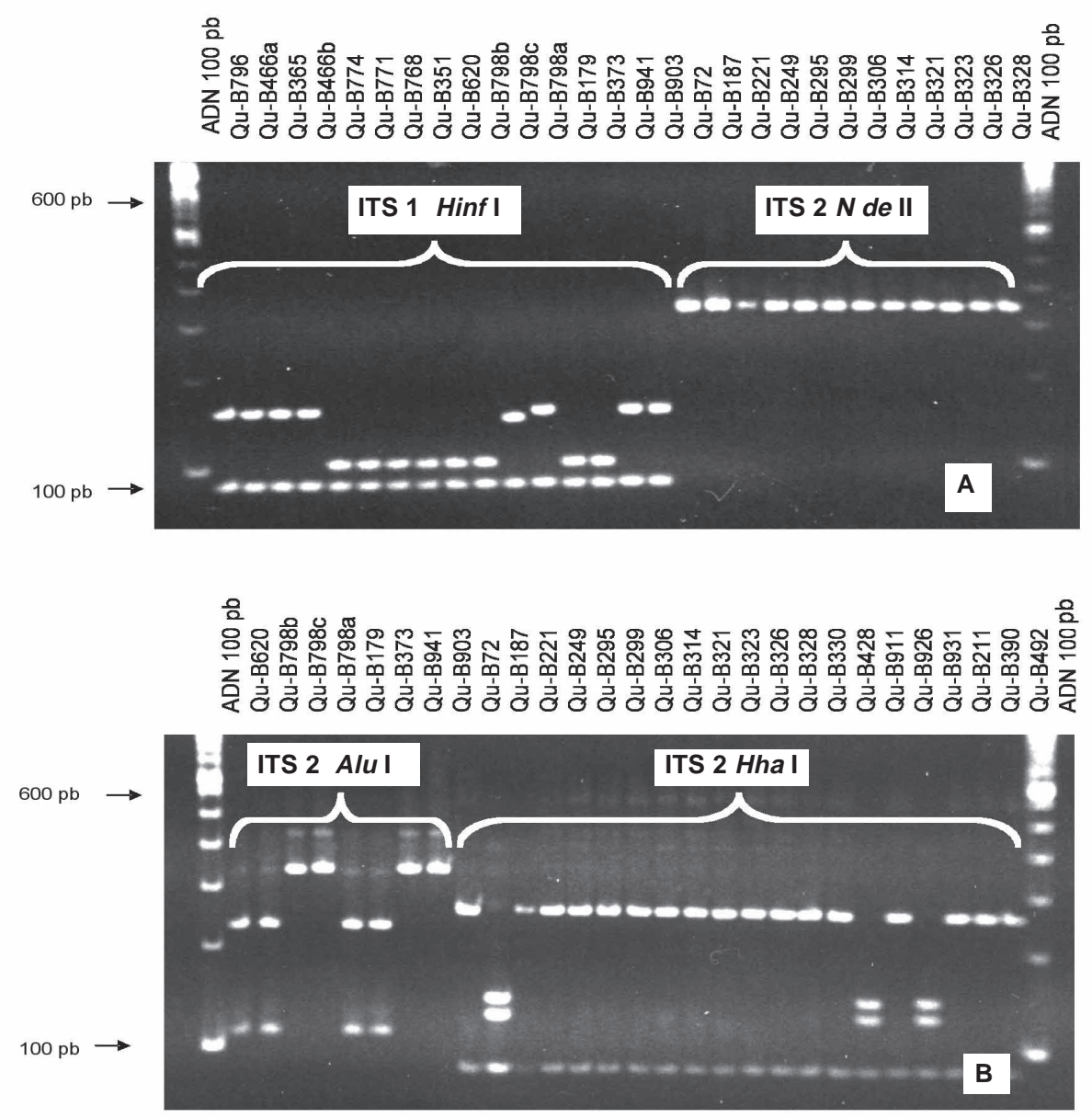

Figura 2. Haplotipos observados en aislamientos chilenos de Beauveria bassiana mediante análisis de PCR-RFLP de las regiones ITS.

Figure 2. Haplotypes observed on Chilean Beauveria bassiana isolates by PCR-RFLP analysis of ITS regions.

Hha I desde 240 a $220 \mathrm{pb}$, con Nde II desde 190 a $180 \mathrm{pb}$ y con Hinf I desde 190 a $30 \mathrm{pb}$ (Figura 2A, Cuadro 2). Hinf I fue la enzima de restricción que detectó el mayor número de sitios de restricción en ITS 1, generando un total de tres haplotipos (Cuadro 2). En conjunto, los productos de PCR de la región ITS 1 digerida por Alu I, Hae III, Hha I, Nde II y Hinf I detectaron un total de cuatro haplotipos.

Por otro lado, la digestión de la región ITS 2 con Alu I generó fragmentos desde 350 a 110 pb, con Hae III desde 190 a $70 \mathrm{pb}$ y, con Hha I desde 290 a 80 pb (Figura 2B, Cuadro 2). Por otro lado, las tres enzimas detectaron dos haplotipos cada una (Cuadro 2). Las enzimas Nde II y Hinf I no detectaron sitios de restricción en la región ITS 2 de los aislamientos. En esta región, los productos de PCR digeridos por Alu I, Hae III y Hha I generaron en conjunto tres haplotipos en las aislaciones analizadas.
Mayor variabilidad fue detectada en la región ITS 1, hecho que se ha detectado en otras especies de hongos (Becerra et al., 2006; Kuninaga et al., 1997; Zare et al., 1999). Al analizar ambas regiones ITS, se detectaron cinco haplotipos en los 36 aislamientos de B. bassiana, sólo los aislamientos Qu-B798c y Qu-B798b, ambos provenientes de Pencahue, VII Región, tienen un haplotipo único y distinto al de los otros aislamientos.

Aunque el análisis de PCR-RFLP de las regiones ITS 1 y 2 detectó diversidad genética en esta especie, los aislamientos no fueron completamente discriminados entre ellos, como ocurrió con los 20 partidores de RAPD. Esta situación fue corroborada con el coeficiente de similitud promedio obtenido con los ITS $(83,7 \%$ ) (Cuadro 3), superior al $42,3 \%$ obtenido mediante RAPD. 


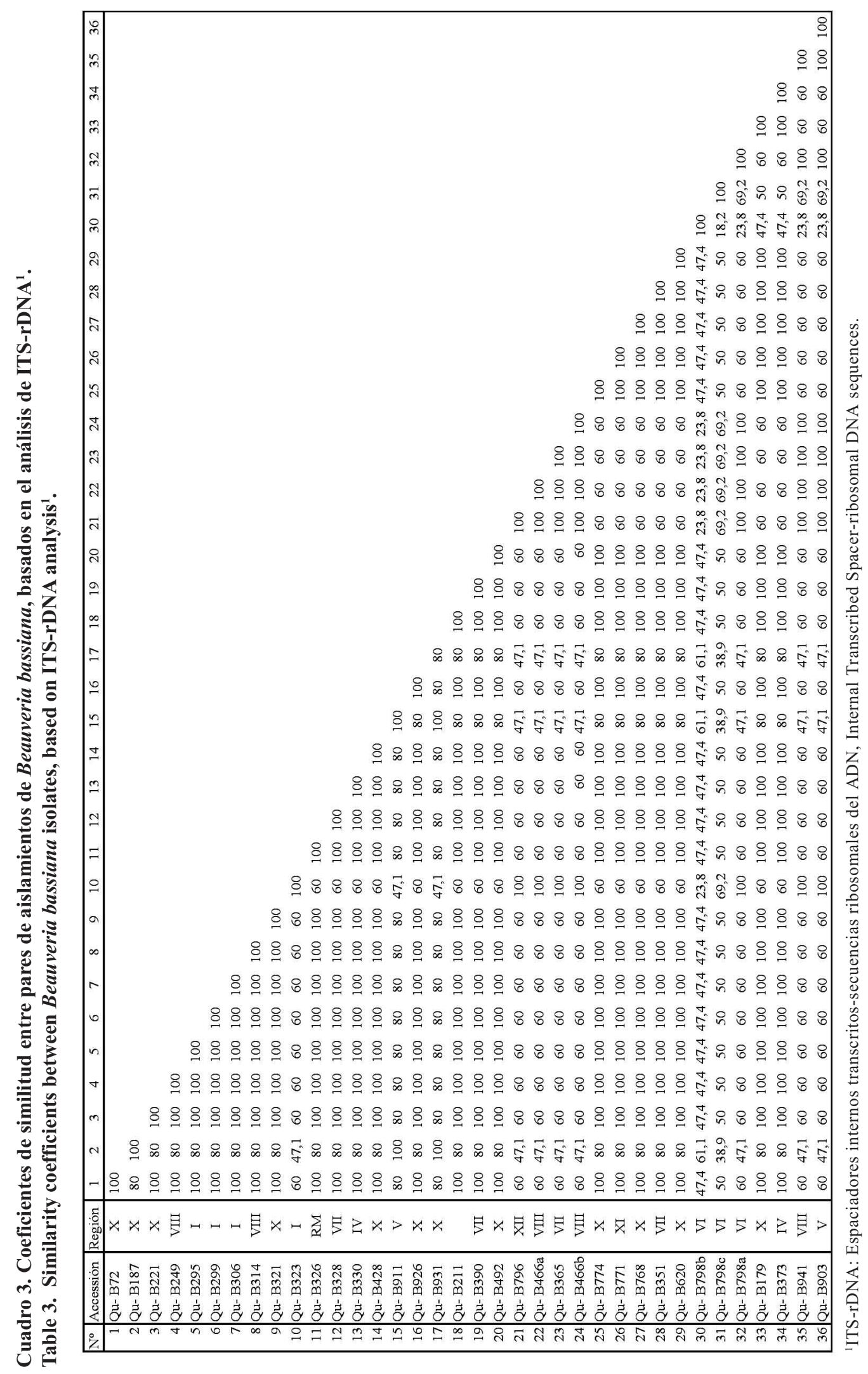




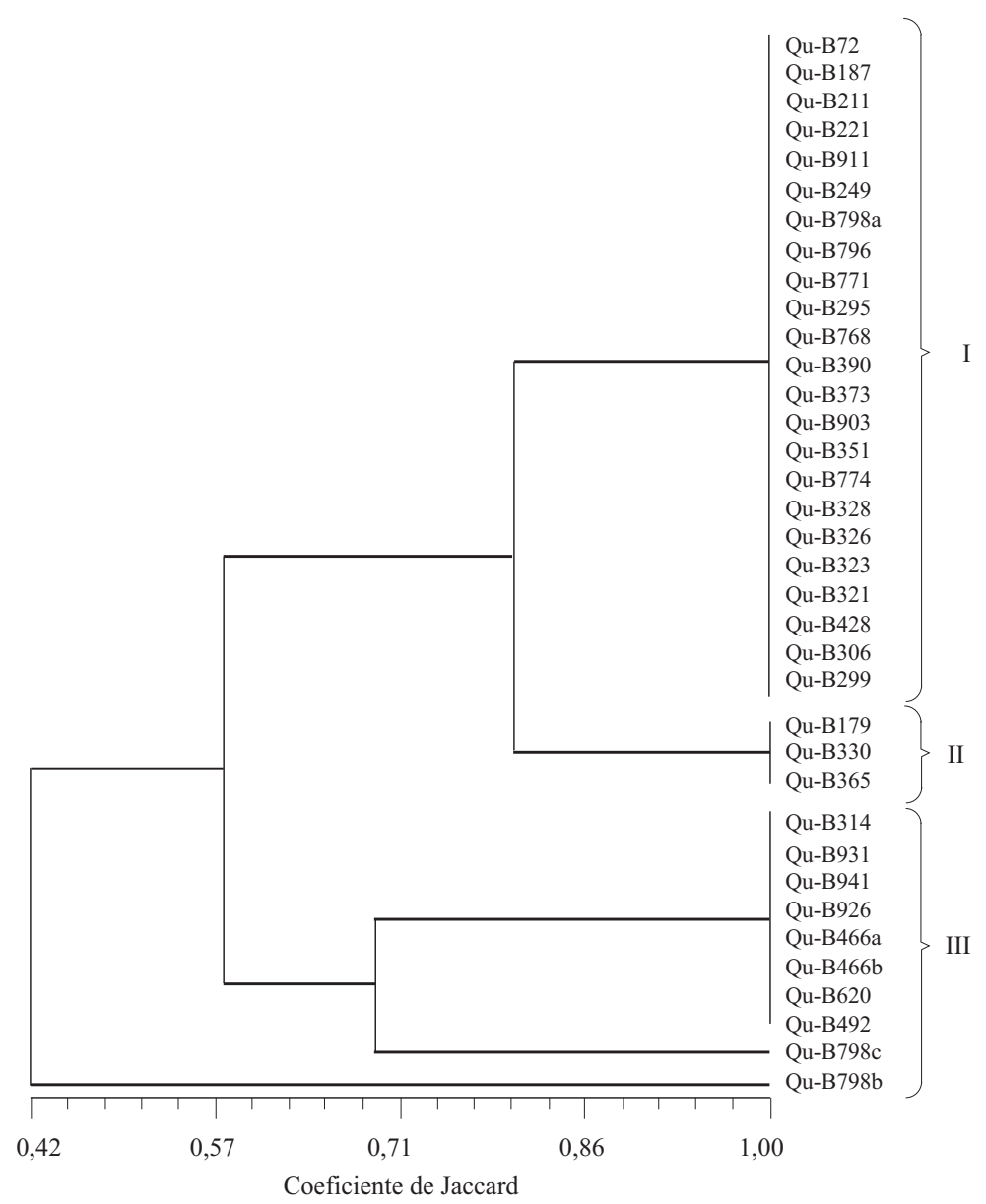

Figura 3. Dendrograma generado del análisis PCR-RFLP de las regiones ITS aislados de Beauveria bassiana chilenos. Figure 3. Dendrogram from PCR-RFLP analysis of ITS regions of Chilean Beauveria bassiana isolates.

El dendrograma indica la presencia de tres grupos distantes genéticamente y dos aislamientos separados genéticamente de los otros genotipos (Figura $3)$. Sin embargo, existe un alto porcentaje de aislamientos idénticos dentro de cada grupo (I, II y III). Por ejemplo, en el grupo I, 23 aislamientos (64\%) presentaron el mismo haplotipo e incluye genotipos colectados en una amplia área geográfica, desde la I a la XII regiones. Un segundo grupo incluyó tres aislamientos de diversas regiones y el tercer grupo de ocho aislamientos $(22 \%)$, los cuales también presentaron un haplotipo idéntico. Dos aislamientos, Qu-B798b y Qu-B798c, fueron genéticamente diferentes al resto y se ubicaron separadamente del resto de los genotipos, aunque ambos provienen de una misma localidad. El coeficiente de correlación cofenético entre la matriz cofenética y los datos originales de los ITS fue de 0,98 . Este valor fue alto al igual que con RAPD y mostró que la matriz original está bien representada en el dendrograma. Es de importancia señalar que el dendrograma generado por los datos de ITS agrupó a los aislamientos de manera muy similar a los RAPD. Además, los ITS no determinaron una relación entre la diversidad genética de los aislamientos y el origen geográfico de éstos. El caso extremo fue el de los aislamientos Qu-B798a, Qu-B798b y Qu-B798c colectados desde el suelo en la localidad de Pencahue, Fundo Bagio (lat $34^{\circ} 20^{\prime} ; 71^{\circ} 11^{\prime}$ ), VII Región. Estos aislamientos presentaron un patrón genético completamente distinto, aún para los ITS, marcadores moleculares que son considerados como conservados.

El análisis de las secuencias ribosomales del ADN (rADN), mediante el diseño de partidores de ITS específicos, ha probado ser eficaz en la resolución del perfil taxonómico del género Beauveria (Hege- 
dus y Khachatourians, 1993; Hegedus et al., 1998) y en la identificación de razas en Metarhizium anisopliae var. anisopliae (Rodríguez et al., 2004).

\section{Identificación de aislamientos}

Al implementar un sistema de control biológico, es importante tener un buen sistema de identificación de los aislamientos que están siendo usados, como una forma de medir la eficiencia de la aplicación y determinar la posible infección que realizan las poblaciones naturales, junto al aislado aplicado en forma artificial (Coates et al., 2002).

En el caso específico de B. bassiana, los RAPD detectaron un mayor grado de diversidad entre los aislamientos. Resultados que concuerdan con aquellos obtenidos por Bidochka et al. (1994), quienes determinaron una gran variabilidad entre aislamientos.

Por otro lado, el uso de los ITS para fingerprinting es más conservador, vale decir, su capacidad discriminatoria es menor. Aunque este marcador detectó variabilidad en B. bassiana con una gran reproducibilidad, muchos de los aislamientos compartieron el mismo haplotipo, haciendo imposible la discriminación entre ellos. Con excepción de Qu-B798c, que fue identificado como genéticamente distinto al resto de los aislamientos, mediante RAPD e ITS.
Basados en estos resultados, los dos marcadores podrían ser usados en forma conjunta para identificar aislamientos de interés comercial. Como también sería recomendable el uso de otros marcadores para complementar este estudio.

\section{CONCLUSIONES}

- Los RAPD e ITS detectaron variabilidad genética en aislamientos chilenos de Beauveria bassiana.

- El análisis de RAPD detectó mayores niveles de diversidad que el análisis de los ITS.

- Los RAPD e ITS, en general, no detectaron asociación entre los aislamientos provenientes de una misma región geográfica.

- En Beauveria bassiana chilena, la región ITS 1 fue más variable que la región ITS 2.

- Los ITS detectaron una escasa diversidad genética en aislamientos chilenos de Beauveria bassiana, por lo cual la discriminación entre aislamientos no fue posible.

\section{RECONOCIMIENTOS}

Los autores desean agradecer a la Ingeniero Agrónomo Sra. Macarena Gerding y a la Técnico Forestal, Sra. Cecilia Santelices por su colaboración en el cultivo de los HEP.

\section{LITERATURA CITADA}

Azevedo, J.L., y I.S. Melo. 1998. Controle microbiano de insectos - pragas e seu melhoramento genético. Controle Biológico 1:69-93.

Becerra, V., M. Paredes, C. Rojo, A. France, and J. Durán. 2006. Intraspecific differentiation of Chilean Metarhizium anisopliae var. anisopliae revealed by RAPD, SSR and ITS. Genet. Molec. Biol. In press.

Bidochka, M.J., M.A. McDonald, R.J. St. Leger, and D.W. Roberts. 1994. Differentiation of species and strains of entomopathogenic fungi by random amplification of polymorphic DNA (RAPD). Curr. Genet. 25:107113.

Bidochka, M.J., S.R.A. Walsh, M.E. Ramos, R.J. St. Leger, J.C. Silver, and D.W. Roberts. 1995. Pathotypes in the Entomophaga grylli species complex of grasshopper pathogens differentiated with random amplification of polymorphic DNA and cloned DNA probes. Appl. Environ. Microbiol. 61: 556-560.
Buscott, F., D. Wipf, C. Di Battista, J.C. Munch, B. Botton, and F. Martin. 1996. DNA polymorphism in morels: PCR/RFLP analysis of the ribosomal DNA spacers and microsatellite-primed-PCR. Mycol. Res. 100:63-71.

Coates, B., R. Hellmich, and L. Lewis. 2002. Allelic variation of a Beauveria bassiana (Ascomycota: Hypocreales) minisatellite is independent of host range and geographic origin. Genome 45:125-132.

Couteaudier, Y., M. Viaud, C. Neuveglise, P. Bridge, and J. Clarkson. 1998. Combination of different independent molecular markers to understand the genetic structure of Beauveria populations. p. 95-104. In Bridge P., Couteaudier Y. (eds.). Molecular variability of fungal pathogens. $\mathrm{CAB}$ International, Wallingford, UK.

Ferron, P., J. Fargues, and G. Riba. 1991. Fungi as microbial insecticides against pest. 733 p. Handbook of applied mycology. Marcel Dekker, Inc., New York, USA. 
France, A., M. Gerding G., M. Gerding P., y A. Sandoval. 2000. Patogenicidad de una colección de cepas nativas de Metarhizium spp. y Beauveria spp. en Aegorhinus superciliosus, Asynonychus cervinus y Otiorhynchus sulcatus. Agric. Téc. (Chile) 60:205-215.

France, A., M. Gerding, y A. Sandoval. 2002. Patogenicidad de aislamientos de Beauveria bassiana en adultos de Asynonychus cervinus (Coleoptera: Curculionidae). Agric. Téc. (Chile) 62:489-496.

Gaitan, A., A. Valderrama, G. Saldarriaga, P. Velez, and A. Bustillo. 2002. Genetic variability of Beauveria bassiana associated with the coffee berry borer (Hypothenemus hampei) and other insects. Mycol. Res. 11:1307-1314.

Glare, T., and A. Inwood. 1998. Morphological and genetic characterization of Beauveria spp. from New Zeland. Mycol. Res. 102:250-256.

Hegedus, D., and G. Khachatourians. 1993. Identification of molecular variants in mitochondrial DNAs of members of the genera Beauveria, Verticillium, Paelomyces, Tolypocladium, and Metarhizium. Appl. Environ. Mycrobiol. 59:4283-4288.

Hegedus, D., T. Pfeifer, D. Mulyk, and G. Khachatourians. 1998. Characterization and structure of the mitochondrial small rRNA gene of the entomopathogenic fungus Beauveria bassiana. Genome 41:471-476.

Iturralde, M.J. 2005. Identificación genética de hongos. Sociedad Micológica de Madrid. Disponible en http: //www.socmicolmadrid.org/noti/noticias 30.html Leído el 24 mayo, 2005.

Kretzner, A.M., R. Molina, and J.W. Spatafora. 2000. Microsatelite markers for the ectomycorrhizal basidiomycete Rhizopogon vinicolor. Mol. Ecol. 9:1190-1191.

Kuninaga, S., T. Natsuaki, T. Takeuchi, and R. Yokosawa. 1997. Sequence variation of the rDNA ITS regions within and between anastomosis groups in Rhizoctonia solani. Curr. Genet. 32:237-243.

López, L.V., y H. Börjes. 2001. Biodiversidad del suelo: control biológico de nemátodos fitopatógenos por hongos nematófagos. Cuad. Biodiversidad 6:12-15.

Maurer, P., Y. Coutaeudier, P.A. Girard, P.D. Bridge, and G. Riba. 1997. Genetic diversity of Beauveria bassiana and relatedness to host insect range. Mycol. Res. 101:159-164.

Mulock, B., and L. Chandler. 2000. Field-cage studies of Beauveria bassiana (Hyphomycetes: Moniliaceae) for the suppression of adult western corn rootworm, Diabrotica virgifera (Coleoptera: Chrysomelidae). Biocontrol Sci. Technol. 10:51-60.

Neuvéglise, C., and Y. Brygoo. 1994. Identification of group-I introns in the $28 \mathrm{~s}$ rDNA of the entomopathogenic fungus Beauveria brogniartii. Curr. Genet. 27:38-45.
Neuvéglise, C., Y. Brygoo, B. Vercambre, and G. Riba. 1994. Comparative analysis of molecular and biological characteristics of strains of Beauveria brogniartii isolated from insects. Mycol. Res. 98:322328.

Piatti, P., F. Cravanzola, P. Bridge, and O. Ozino. 1998. Molecular characterization of Beauveria brongniartii isolates obtained from Melolontha melolontha in Valle d'Aosta (Italy) by RAPD-PCR. Lett. Appl. Microbiol. 26:317-324.

Rodríguez, R.H., S.A. Lanza, and C.L. Messias. 2004. Detection of Metarhizium anisopliae var. anisopliae within infected sugarcane borer Diatraea saccharalis (Lepidoptera, Pyralidae) using specific primers. Genet. Mol. Biol. 27:245-252.

Rohlf, F.J. 2000. NTSYS-PC Numerical taxonomy and multivariate analysis system. Version 2.1. 189 p. Exeter Publications, New York, USA.

Shih, H.L., C.P. Lin, R.F. Liou, and S.S. Tzean. 1995. Complete nucleotide sequence of Beauveria bassiana 5.8S rRNA coding gene and flanking internal transcribed spacers. DNA Sequence 5:381-383.

Sivaramakrishnan, S., S. Kannan, and S.D. Singh. 2002. Genetic variability of Fusarium wilt pathogen isolates of chickpea (Cicer arietinum L.) assessed by molecular markers. Mycopathologia 155:171-178.

Sneath, P.A., and R.R. Sokal. 1973. Numerical taxonomy. 573 p. Freeman, San Francisco, California, USA.

Valderrama, F., A. Cristanchio, and C. Chaves. 2000. Analysis of genetic variability of the entomopathogenic fungus Beauveria bassiana by RAPD markers. Revista Colombiana de Entomología 26:25-29.

White, T.J., T. Bruns, S. Lee, and J. Taylor. 1990. Amplification and direct sequencing of fungal ribosomal RNA genes for phylogenetics. p. 315-322. In M.A. Innis, D.H. Gelfand, J.J. Sminsky, and T.J. White (eds.). PCR Protocols: A guide to methods and applications. Academic Press, Inc., New York, USA.

Williams, J.G.K., A.R. Kubelik, K.J. Livak, J.A. Rafalski, and S.V. Tingy. 1990. DNA polymorphisms amplified by arbitrary primers are useful as genetic markers. Nucleic Acids Res. 18:6531-6535.

Zare, R., V. Kouvelis, M. Typas, and P. Bridge. 1999. Presence of a $20 \mathrm{bp}$ insertion/deletion in the ITS 1 region of Verticillium lecanii. Lett. Appl. Microbiol. 28:259-262.

Zurek, L., and B.A. Keddie. 2000. Beauveria bassiana (Balsamo) Vuillemin-a promising microbial control agent of the satin moth (Lepidoptera: Lymantriidae). Biocontrol Sci. Technol. 10:641-644. 